
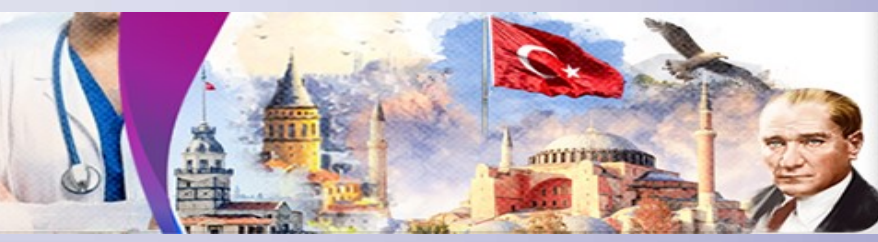

\title{
Readability Of Abstracts Of The 36th Annual European Society Of Regional Anesthesia And Pain Therapy (ESRA) Congress 2017
}

S. Güven Köse ${ }^{1}$, H.C. Kose², D.T. Thomas ${ }^{3}$, S. Tulgar ${ }^{4}$

${ }^{1}$ University of Health Science Kartal Dr. Lütfi Kırdar Education and Research Hospital, Anesthesiology and Reanimation, Istanbul, Turkey. ${ }^{2}$ Maltepe State Hospital, Anesthesiology and Reanimation, Istanbul, Turkey. 3 Maltepe University Faculity of Medicine, Department of Medical Education, Istanbul, Turkey.

${ }^{4}$ Maltepe University faculity of Medicine, Anesthesiology and reanimation, Istanbul, Turkey

ESRA8-

0454

\section{Background and Aims:}

Abstracts accepted and presented in international congress usually published and have traditionally been deficient in crucial information due to the limited word count. The readability of abstracts is scarcely evaluated. Our aim in this study is to evaluate the readability of abstracts accepted as oral presentations or e-posters at ESRA 2017 Congress and published.

\section{Methods:}

The article published in the Journal of Regional Anesthesia and Pain Medicine titled "Abstracts and Highlight Papers of the 36th Annual European Society of Regional Anesthesia \& Pain Therapy (ESRA) Congress 2017" was analyzed. The Gunning Fog index (GFI) and the Flesch Reading Ease score (FRES) (http://www.readabilityformulas.com) were used to assess the readability of the abstracts.

\begin{tabular}{|r|r|r|r|}
\hline \multicolumn{1}{|c|}{ Gunning Fog Index } & & Flesch Reading Ease score (FRES) & \\
\hline$<5$ (Very easy) & 0 & $70-100$ (Easy) & 0 \\
\hline $\mathbf{5 - 1 2}$ (Readible) & 97 & $\mathbf{6 0 - 6 9}$ (Standart) & 105 \\
\hline $12-20$ (too difficult) & 306 & $\mathbf{3 0 - 5 9}$ (Difficult) & 301 \\
\hline$>20$ Confusing & 3 & $\mathbf{0 - 2 9}$ (Confusing) & 0 \\
\hline
\end{tabular}

\section{Results:}

All of 406 abstracts were evaluated. The GFI averages of the abstracts were 15.13 (min: 9.02, max: 21.4) and the readability of the vast majority was evaluated as very hard (above 12 is too difficult).

The FRES scores of the abstracts averaged 39.14 ( $\min : 29.8$, max: 68.21) and he readability of the vast majority was evaluated as fairly difficult (between 50-59) and difficult (between 30-49).

\section{Conclusions:}

The readability of the vast majority of abstracts accepted and published in the ESRA 2017 congress was evaluated as difficult. Word limitations can be considered as one of the reasons for this situation. It may be useful to extend the woro boundary or add the readibility score tool to the abstractsubmission system. 